\title{
An Analysis on the Role of Universal Grammar in Second Language Acquisition
}

\author{
Buhan Pan* \\ School of Foreign Languages, Huazhong Agricultural University, Wuhan 430070, Hubei, China \\ panbuhan@163.com
}

Keywords: Universal Grammar; Accessibility; SLA; Learning process.

\begin{abstract}
This study examines the Universal Grammar's complicated role in second language learning. The paper firstly presents a brief description of the UG and a review of recent studies in SLA with UG approach. Then the paper discusses the relevance of Universal Grammar to SLA from five aspects: accessibility of UG, L1 and L2 acquisition differences, learning models, poverty-of-the-stimulus argument, and debates on principles and parameters in SLA. Finally, pedagogical implications are proposed.
\end{abstract}

\section{Introduction}

With the development of transformational-generative grammar, Chomsky formulated the theory of Universal Grammar (UG) in his Lectures on Government and Binding [1]. Since the UG directly sheds light on how languages are acquired and what languages consist of, it arouses many applied linguists' interest to conduct research on the use of principles and parameters model on second language acquisition (SLA) in the 1980s [2]. In recent years, the UG has continued to influence and inspire a lot of studies on SLA, and has been viewed as a particular linguistic approach to SLA research. As a linguistic theory, Universal Grammar is a little different from the other theories concerned in SLA research. It is a property theory which emphasizes on "the underlying linguistic knowledge in second-language learners' minds", while the other theories (transition theory) pay more attention to the details in learning process [3].

\section{Universal Grammar and UG Approach in SLA}

Chomsky [4] once reflects on the essence of Universal Grammar and views it as "the system of principles, conditions, and rules that are elements or properties of all human languages". This definition of UG can be understood in three senses. First, Universal Grammar is a theory of "properties" or knowledge, not of behavior [2]. The goal of the theory is to describe and explain the innate language faculty. Second, the UG theory can be applied to many languages. The elements in the grammar are "universal" or common to any languages. Third, the language knowledge consists of principles universal to all languages and different parameters from one language to another [2, 5]. To some extent, UG can be viewed as a theory of principles and parameters.

The main focus of Universal Grammar is language acquisition. In the framework of the theory, language acquisition is a process of learning how to apply principles to a particular language and set parameters by selecting the appropriate value according to the input data. UG helps learners to establish a core grammar with unmarked rules that are constrained by UG $[5,6]$. Learners can also gain some marked rules through elements of language, and form a peripheral grammar which is not determined by UG.

The UG approach to SLA research begins in the 1970s, due to an awareness of similarities between first language acquisition (FLA) and second language acquisition [3]. Researchers wonder whether the Universal Grammar can still function in SLA. However, SLA is quite different from FLA. With the 
presence of L1 and its grammar, the situation in SLA is very complicated. In the 1980s and early 1990s, the focus of the research is placed on the "access to UG" question - whether UG is available to adult L2 learners or not $[7,8]$.

In recent years, two trends can be seen in the research. Firstly, people accept the complications in SLA, and shift their attention from overall accessibility issue to the availability of specific features of UG in SLA [7]. Secondly, recent work aims at determining whether L2 representations are constrained by the UG principles. Thus, whether L2 learners can have the same mental representation as L1 learners is not that important, and "L2-L1 differences are no longer central" [7]. Particularly, recent studies in UG approach pay more attention to "poverty of the stimulus" (POS) phenomena [8]. However, Hawkins [7] advances that attempts to explain L2-L1 differences are still essential to deepen our understanding of the nature of SLA and UG involvement. From the following section on, we will examine the Universal Grammar approach from five specific areas of SLA research: accessibility of UG, L1 and L2 acquisition differences, learning models, poverty-of-the-stimulus argument, and debates on principles and parameters in SLA.

\section{Accessibility of UG}

Mitchell \& Myles [3] has made a comprehensive review of different theoretical positions regarding access to UG in SLA. These positions can be generally classified into three groups: no access, full access and partial access to UG. Proponents of no access position argue that there is a critical period for language acquisition. After that period, Universal Grammar will be no longer available [9]. Adult L2 learners thus have to resort to other learning mechanisms or strategies to learn L2. Their second language is learnt in the similar way as any other aspect of knowledge.

Researchers who adopt full access position believe that Universal Grammar continues to operate for adult L2 learners. All the parameters of UG are available and can be reset. Some encouraging studies have supported this belief. Besides, some researchers also realize the L1 transfer in the process of parameter resetting. L2 learners are thought to transfer all the parameter-settings of L1 at the very beginning. Then learners will examine the L1 settings by accommodating them to L2 input. If they fail to conform to L2, learners will revise their initial hypothesis. In this way, parameter resetting can be achieved. In this full transfer and full access hypothesis, UG functions indirectly through L1 in the first stage, and then directly for resetting [8].

Supporters of partial access hypothesis also realize the important role of L1 in SLA, and propose that UG can only affect SLA indirectly via the L1. That is to say, only those principles and parameter settings acquired in L1 are available to L2 learners. If there are some other different parameter settings in L2, learners have to use other mechanisms and problem-solving strategies to learn the new language [10].

\section{L1 and L2 Acquisition Differences}

One of the reasons for different positions in "access to UG" issue lies in the differences between L1 and L2 acquisition. In the UG context, Hawkins [7] highlights the L2-L1 differences analysis, and summarizes several contextual differences in SLA: (1) L1 is already present; (2) L2 learners are cognitively mature, but L1 learners have to develop their language competence along with other cognitive capacities; and (3) Input involves written as well as spoken language.

Thomas [11] points out some crucial differences between child L1 learning and adult L2 learning, which involves the following: L2 learning may encounter fossilization and L1 transfer; L2 learners have different motivations for learning an L2. Mitchell \& Myles [3] also argue that L2 learners' needs are very different, because they are already "successful communicators in one language". Their ability to solve problems and deal with abstract concepts is relatively high. However, few L2 learners succeed 
in achieving near native competence, because L2 learners may easily feel satisfied with their interlanguage and their ability to communicate effectively. Thus, fossilization occurs [12].

Besides the above mentioned differences in SLA, White [13] also discusses L1 and L2 acquisition differences from the perspective of instruction and correction. It is generally believed that "explicit instruction and negative evidence" are not useful in L1 acquisition, whereas they are considered to be effective and necessary in second language learning.

\section{Learning Models}

Chomsky [14] proposes the Language Acquisition Device (LAD) hypothesis to explain how human language is acquired. In principle, the LAD model can demonstrate the process of acquisition of any natural language. Take L1 acquisition as an example. First, L1 input data are provided. Then the input in processed in the black box which contains UG principles and parameters. Finally, L1 grammar is produced.

In the context of SLA, we can adapt the LAD model to L2 learning by simply extending the model to take in L2 input. However, Cook and Newson [2] argue that the LAD diagram cannot represent the initial state of L2 learning owing to the differences in L1 and L2 acquisition. In FLA, the initial state can be called as So which contains no language-specific knowledge. Children develop their L1 and finally reach a steady state Ss of knowing everything of the language. In SLA, the initial state Si of learners is quite different from the So of L1, since L2 learners already know L1 grammar. In the normal situation, $\mathrm{Si}=(\mathrm{So}+\mathrm{Ss})$. What's more, since most L2 learners can hardly reach native competence of L1, their learning process will not achieve Ss, but terminate at St. Thus, L2 learning proceeds from Si to St. Both the initial state and the final state of SLA are different from FLA.

\section{Poverty-of-the-Stimulus Argument}

The poverty-of-the-stimulus argument or "Plato's problem" was first raised by Chomsky in 1987, and regarded as an important landmark in theory development [7]. The argument touches the very heart of the UG model: if some aspects of language knowledge are not learnt from the external sources, they must be "built in to the human mind" [15]. The structure of the argument is summarized into four steps by Cook [16]: (1) a L1 speaker knows a particular aspects of syntax; (2) this aspect of syntax cannot be learnt from the L1 input; (3) this aspect of syntax is not learnt from outside; and (4) this aspect of syntax is built-in to the mind.

Since this argument initially works for L1 acquisition, we may encounter some problems when it is used for examining SLA. Firstly, the piece of knowledge in Step (1) is common to all speakers in FLA, while it may vary from person to person in SLA. Secondly, in Step (2), variation in input data is irrelevant to FLA, while L2 learning may be influenced by L1 transfer and some other type of evidence in the classroom which is unavailable to L1 child. Thirdly, Step (1) and Step (2) need to be modified because of different knowledge and evidence between L1 and L2 acquisition. Fourthly, the modification of the first two steps will increase the uncertainty of Step (3) and Step (4). Indeed, the argument cannot be easily employed to L2 learning due to the complex nature of SLA [15]. In my opinion, however, the poverty-of-the-stimulus argument is still an original method that can be properly used to examine the availability and functions of UG to L2 learning.

\section{Debates on Principles and Parameters in SLA}

In SLA, UG principles are generally thought to be available, since L2 learners do not violate those principles in producing their interlanguages. This fact indicates that interlanguages are also "qualified" languages constrained by Universal Grammar. Current debates in research pay more attention to the availability of specific parameters and parameter resetting. First, research questions tend to be more 
focused [15]. E.g. why some parameters are successfully reset in SLA? What's the role of the L1 settings in L2 learning? Second, with the development of the Minimalist Program, researchers begin to argue the availability of functional categories in the early stage of SLA [3]. Since the functional categories are essential for parameter resetting, the debate is likely and worthwhile to go on for some time. Besides the absence and presence approaches to the issue, some researchers advance a structure-building approach to L2 development [17].

\section{Implication and Conclusion}

To draw some pedagogical implications for ELT directly from the researches reviewed in the article, two points can be made. Firstly, teachers should provide enough authentic target language materials to raise students' awareness of L1-L2 differences, and facilitate their processes of hypotheses revising and parameters resetting. Secondly, White's [13] suggestions of explicit instruction and correction can still be very useful in English language teaching.

In conclusion, the article discusses the role of Universal Grammar in second language acquisition by reviewing the theory itself and its relevance to five areas in SLA research. The availability of UG is a relatively broad issue, while the other four aspects touch some particular areas of studies. Although the five aspects of the review may overlap to some extent, the overall purpose of the study is to provide some useful accounts of recent development in SLA research from a Universal Grammar perspective.

\section{References}

[1] N. Chomsky, Lectures on Government and Binding, Dordrecht: Foris, 1981.

[2] V. Cook and M. Newson, Chomsky's Universal Grammar: An Introduction, Oxford: Blackwell, 1996.

[3] R. Mitchell and F. Miles, Second Language Learning Theories, London: Hodder Arnold, 2004.

[4] N. Chomsky, Reflections on Language, London: Temple Smith, 1976.

[5] V. Cook, Universal Grammar and Second Language Learning, Applied Linguistics 6, 1, 2-18, 1985.

[6] R. Ellis, Understanding Second Language Acquisition, Oxford: Oxford University Press, 1985.

[7] R. Hawkins, The Theoretical Significance of Universal Grammar in Second Language Acquisition, Second Language Research 17, 4, 345-367, 2001.

[8] L. White, Second Language Acquisition and Universal Grammar, Cambridge: Cambridge University, 2003.

[9] J. Johnson and E. Newport, Critical Period Effects in Second Language Learning: The Influence of Maturational State on the Acquisition of ESL, Cognitive Psychology, 21, 60-99, 1989.

[10] J. Schachter, Maturation and the Issue of Universal Grammar in Second Language Acquisition. In W. Ritchie and T. Bhatia. (Eds.), Handbook of Second Language Acquisition, San Diego, CA: Academic Press, 159-193, 1996.

[11]M. Thomas, Universal Grammar in Second Language Acquisition: A History, New York: Routledge, 2004.

[12]L. Selinker, Interlanguage, International Review of Applied Linguistics, 10, 209-231, 1972.

[13]L. White, Universal Grammar and Second Language Acquisition, Amsterdam/Philadelphia: John Benjamins, 1989. 
[14]N. Chomsky, Current Issues in Linguistic Theory, The Hague: Mouton, 1964.

[15] V. Cook, Linguistics and Second Language Acquisition, London: Macmillan, 1993.

[16]V. Cook, The Poverty-of-the-Stimulus Argument and Multicompetence, Second Language Research, 7, 2, 103-117, 1991.

[17]J. Herschensohn, The Second Time Around: Minimalism and Second Language Acquisition, Amsterdam: John Benjamins, 2000. 